\title{
Heat flux Distribution Model and Transient Temperature Field Analysis in Grinding of Helical Raceway
}

\author{
Zongfu Guo ( $\square$ guozongfu816@163.com ) \\ Hangzhou Dianzi University \\ Jun Yi \\ Hunan University \\ Xiaoping $\mathrm{Hu}$ \\ Hangzhou Dianzi University \\ Jiugen Wang \\ Screw grinding, raceway grinding, grinding temperature \\ Kun Zhao \\ Cixing Group Co., Ltd, Ningbo
}

\section{Research Article}

Keywords: Screw grinding, raceway grinding, grinding temperature

Posted Date: February 28th, 2022

DOI: https://doi.org/10.21203/rs.3.rs-1384537/v1

License: (c) (i) This work is licensed under a Creative Commons Attribution 4.0 International License. Read Full License 


\title{
Heat flux Distribution Model and Transient Temperature Field Analysis in
}

\section{Grinding of Helical Raceway}

\author{
Zongfu Guo ${ }^{12}$, Jun $\mathrm{Yi}^{3}$, Xiaoping Hu², Jiugen Wang', Kun Zhao ${ }^{4}$
}

\begin{abstract}
To solve the problem of low processing efficiency of screw helical raceway by using high-efficiency grinding technology, this paper carried out theoretical, simulation and experimental analysis on the grinding temperature which mainly affects the selection of high-efficiency grinding process parameters. First, based on the distribution characteristics of the grinding allowance of the screw helical raceway, the analysis shows that the geometry of the grinding contact area is trapezoidal. Then, based on the existing triangular heat flux distribution model of the rectangular contact area, two heat flux distribution models of the triangle and the concave triangle are proposed according to the characteristics of the trapezoidal contact area. Finally, the plane grinding experiment was carried out to correct the simulation parameters, and the modified simulation parameters were used to predict the grinding temperature of the screw raceway, so as to achieve the maximum removal efficiency and avoid burns. The analysis results show that the highest temperature in the grinding area is on the lowest point of the helical raceway, and the temperature and temperature gradient in the grinding area obtained by using the concave triangular heat flux distribution model are the highest. By comparing the process parameters for the onset of grinding burns predicted by simulation and experimentally, the temperature predicted by the concave triangle heat flux distribution model in the trapezoidal contact area is higher than the actual temperature, while the temperature predicted by the triangle heat flux distribution model in the trapezoidal contact area is lower than the actual temperature.
\end{abstract}

Keywords: Screw grinding; raceway grinding; grinding temperature

\section{1. introduction}

The threaded screw is used as a transmission component, and the geometric accuracy and surface quality of the helical raceway directly affect the transmission accuracy and service life. The initial shape of the helical raceway of the screw is usually obtained by turning or extrusion, and then a thread grinder is used for grinding. There are still problems of low machining accuracy and production efficiency in the screw grinding technology at this stage, and it is urgent to adopt new processes and new technologies to improve industrial capabilities and technical levels.

High-efficiency grinding technology is to achieve high material removal efficiency and meet certain processing quality by increasing the grinding linear speed and reducing the maximum undeformed cutting thickness of a single abrasive particle ${ }^{[1-3]}$. Among them, the control of grinding temperature is an important factor affecting the selection of high-efficiency grinding process parameters. To obtain the grinding temperature in the grinding area, the method of installing a

Zongfu Guo

guozongfu816@163.com

1. School of Mechanical Engineering Zhejiang University, Hangzhou, 310058

2. School of Mechanical Engineering Hangzhou Dianzi University, Hangzhou, 310018

3. School of mechanical engineering Hunan University of Science and Technology, Xiangtan, 411201

4. Cixing Group Co., Ltd, Ningbo, 315300 thermocouple in the grinding area is generally used for experimental measurement or do simulation analysis based on grinding heat flux theory. Most of the grinding temperature analysis currently carried out is based on the moving heat flux theory proposed by Jaeger ${ }^{44}$, and the arc moving heat flux analysis model [5], the Rayleigh curve heat flow distribution model [6], Random particle discrete temperature model (SGDTM) [7], higher-order function curve heat flux model ${ }^{[8]}$ and so on, are proposed for different processing forms. Aiming at the temperature distribution in free surface grinding, Yi Jun et al. took gear forming grinding as the research object and proposed a three-dimensional grinding arc area equivalent grinding heat flux analysis model ${ }^{[9]}$. Faced with the grinding of the complex contour of the turbine blade root, Miao et al. established a thermal model based on finite element and studied the grinding temperature distribution of the workpiece and the influence of the blade root forming process on the evolution of the grinding temperature [10]. For the small-scale helical raceway, the grinding surface is a complex curved surface in space, and it is very difficult to measure the temperature with thermocouples. Therefore, the finite element simulation method is used to obtain the distribution of the grinding temperature field and the influence law of the process parameters. It is of great significance to study the technology and avoid grinding burns.

In this paper, the theory of grinding heat flux will be analyzed first, and the shape of the grinding 
contact area and the distribution of heat flux will be determined on the basis of the research on the distribution of the helical raceway allowance. Then, the finite element simulation analysis was carried out to determine the temperature field distribution and the maximum temperature during the grinding process of the helical raceway. Finally, it is verified by comparison with the experimental results.

\section{Theoretical analysis of grinding heat}

During the grinding process, a large amount of grinding energy is converted into grinding heat in the grinding area, and a small part is converted into kinetic energy of grinding chips. The escape velocity of the grinding chips from the grinding area can be regarded as the same as the linear velocity of the grinding surface of the grinding wheel. Then the average heat flux density generated in the grinding area during the grinding process is shown in Equation $1^{[11]}$.

$$
q_{t}=\frac{F t \times v_{s}}{b \cdot l_{c}}-\frac{a_{p} \times v_{w} \times \rho \times v_{s}{ }^{2}}{2 l_{c}}
$$

Where, $F_{t}$ is the tangential grinding force, $a_{p}$ is the grinding depth, $b$ is the width of the grinding zone, $v_{s}$ is the grinding wheel speed, $v_{w}$ is the workpiece feed speed, $l_{c}$ is the grinding arc length, $\rho$ is the material density.

The grinding heat generated in the grinding area mainly enters the workpiece, grinding wheel, grinding debris and grinding fluid through heat conduction. The research results of the researcher Howes show that when the grinding temperature exceeds the boiling temperature of the grinding fluid in the grinding zone, the steam on the surface of the workpiece will seriously reduce the cooling effect of the grinding fluid [9], and the main function of the grinding fluid is to cool Workpieces outside the contact area. Therefore, it is concluded that the importance of the grinding fluid in shallow grinding is that its lubricating effect reduces the grinding force in grinding, so when the temperature of the grinding area is higher than the boiling temperature $\mathrm{T}^{\prime}$ of the grinding fluid (for water-based grinding fluid, $\mathrm{T}^{\prime}$ is generally 130 degrees Celsius), and the heat input into the coolant in the grinding area can be ignored. Malkin's research believes that the heat taken away by the wear debris is close to the energy required to melt the wear debris ${ }^{[12]}$, and the energy ecc required for melting of various steels is about $6 \mathrm{~J} \cdot \mathrm{mm}^{-3}$. The heat flow per unit area in the grinding area is $q_{t}=P /\left(b \cdot l_{c}\right)$. The heat flow into the workpiece is $q_{w}=R_{w} \cdot q_{t}$. Based on Hahn's model [13], the distribution ratio $R_{w s}$ between workpiece and grinding wheel is

$$
R_{w s}=\frac{R_{W}}{R_{W}+R_{S}}=\left(1+\frac{0.97 k_{g e}}{\sqrt{r_{0} \cdot v_{s} \cdot(k \rho c)_{W}}}\right)^{-1}
$$

where, $k_{g e}$ is the thermal conductivity of the abrasive particles, $r_{0}$ is the effective radius of the contact between the abrasive particles and workpiece. Considering the influence of the wear debris on the heat flow, the final distribution ratio $R_{w}$ is smaller than $\mathrm{R}_{\mathrm{ws}}$.

The research results show that the heat flux density in the contact area of the workpiece is not uniformly distributed. Taking into account the inconsistency in the thickness of the grinding contact arc, Bei proposed a triangular distributed heat flux. Practice shows that this theory is more in line with reality ${ }^{[14]}$. Kim proposed a scalene triangle heat flux distribution model, and the research shows that the model is suitable for creep feed grinding ${ }^{[15]}$. Mao Cong et al. proposed a parabolic heat flux distribution model, and the calculation results of the model are in good agreement with the experimental measurements ${ }^{[16]}$. Based on the triangular heat flux distribution model, Li proposed a polynomial curve heat flux distribution model according to the characteristics of cylindrical grinding [17]. The helical raceway studied in this paper is significantly different from the plane grinding or cylindrical grinding previously studied, so a special study on the heat flux distribution is required.

\section{Research on heat flux distribution in}

\section{helical raceway grinding}

Figure 1a shows a schematic diagram of the processing motion of the screw on the thread grinding machine. It can be seen from the figure that the screw helical raceway and the outer cylindrical surface are simultaneously ground by the forming grinding wheel. Figure $1 \mathrm{~b}$ is a schematic diagram of the grinding contact arc length. Since the grinding depth is very small compared to the diameter of the grinding wheel, the geometric contact arc length between the grinding wheel and the workpiece can be approximately equal to the half-chord length, and the grinding arc length can be expressed by equation 3 .

$$
l \approx k \sqrt{\frac{R_{G}\left(2 d R_{s}-d^{2}\right)}{R_{G}+R_{s}-2 d}-\left(\frac{2 d R_{s}-d^{2}}{2\left(R_{G}+R_{s}-2 d\right)}\right)^{2}}
$$

where, $k$ is the proportional coefficient, $R_{G}$ is the radius of the grinding wheel, $R s$ is the equivalent radius of the grinding position of the screw.

$$
R_{S}=\frac{\sqrt{P^{2}+(\pi D)^{2}}}{2 \pi}
$$

where $\mathrm{P}$ is the lead, $\mathrm{D}$ is the diameter of the screw.

Figure 1c shows the radial grinding allowance distribution from the start profile of the screw to the target profile. It can be seen from the figure that the depth of the grinding allowance in the raceway is significantly larger than that of the outer cylindrical surface of the screw. The radial grinding allowance 
in the raceway area is basically the same, but the grinding temperature is mainly affected by the tangential grinding force related to the normal grinding depth, so it is necessary to research the normal grinding depth along the raceway arc length. According to the equation 3 of the contact arc length in the grinding area and the normal grinding depth distribution in Figure 1c, the contact arc length variation along the raceway arc length distribution shown in Figure 1d can be solved. It can be found from the figure that there is an obvious change in the contact arc length at the edge of the raceway. Therefore, it is considered that the solution result obtained by using the trapezoidal contact area is closer to the real situation than that obtained by using the rectangular contact area.
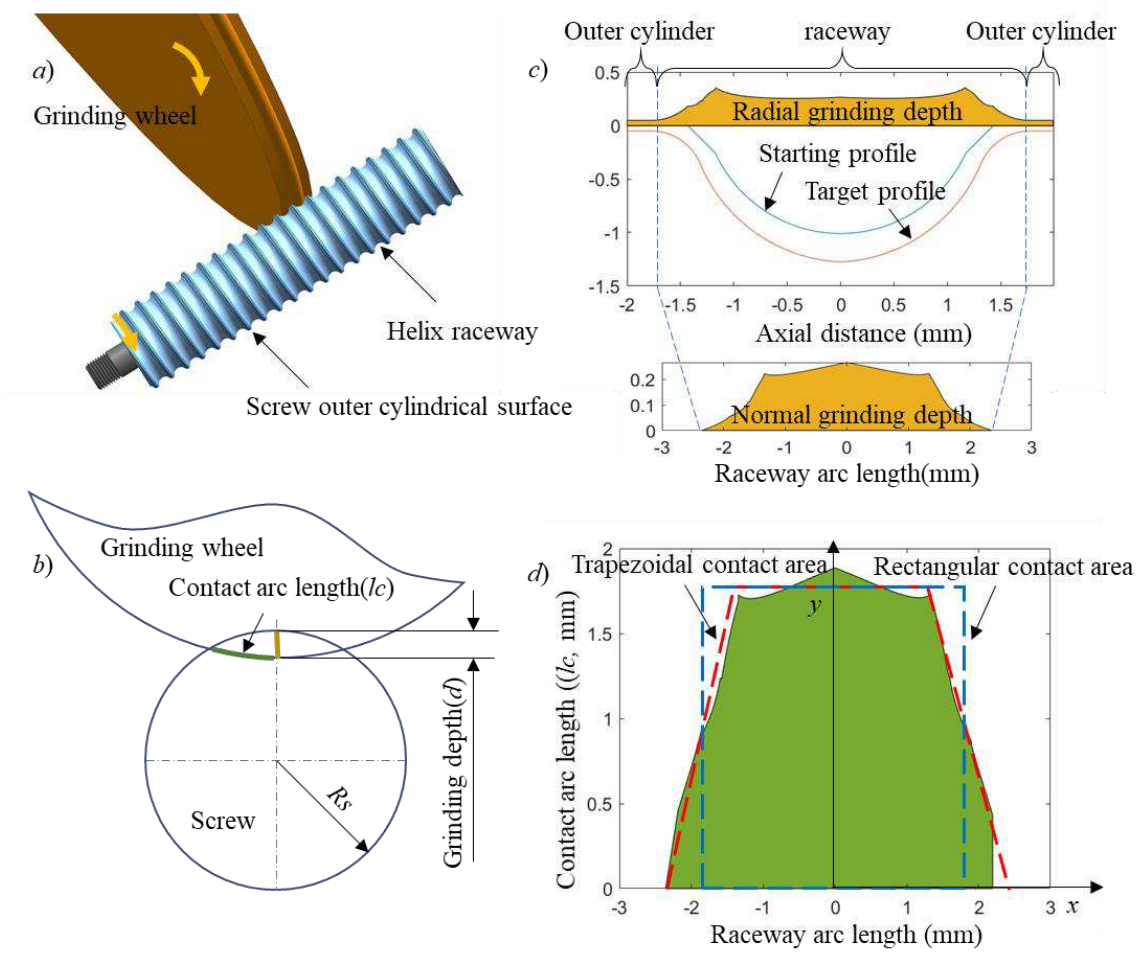

Fig.1 Geometry analysis of the grinding contact area of screw helical raceway (a)

the relative movement and position of the screw and the grinding wheel (b) schematic diagram of contact arc length (c) radial and normal grinding depth (d) the shape of contact area

Since the area of the trapezoidal contact area and the rectangular contact area are the same, when the average heat flux distribution model is used, the average heat flux density of the trapezoidal contact area is equal to the average heat flux density $q_{w}$ of the rectangular contact area. When the triangular heat flux distribution model is used, the distribution of the heat flux density $q_{R_{-} T}$ in the rectangular contact area along the grinding contact arc length can be calculated as the following equation 5 .

$$
q_{R_{-} T}(y)=\frac{2 y}{l_{c}} q_{w}
$$

Where, $\mathrm{y}$ is the distance from a point on the contact area to the starting contact line.

For the trapezoidal contact area, two different heat flux distribution models are proposed in this paper under the premise of ensuring that the total heat flow is consistent with the triangular heat flux distribution in the rectangular contact area. One is the linearly changing trapezoidal contact surface triangle heat flux distribution model, and the distribution of the heat flux density $q_{T_{-} T}$ along the grinding contact arc length is obtained by solving the following equation.

$$
q_{T_{-} T}(y)=\frac{y}{l_{c}}\left(\frac{3\left(L_{1}+L_{2}\right)}{L_{1}+2 L_{2}} q_{w}\right)
$$

Where, L1 is the length of the long side of the trapezoidal contact area, and L2 is the length of the short side of the trapezoidal contact area. The other is to keep the same heat flux density at the same length of the contact arc. The distribution of the heat flux density $q_{T_{-} E}$ along the grinding contact arc length is obtained by solving the following equation.

$$
q_{T_{-} E}(y)=\frac{\left(L_{1}+L_{2}\right) y}{\left(L_{2}-L_{1}\right) y+L_{1} l_{c}} q_{w}
$$

It can be seen from Equation 7 that when the contact area changes from a rectangle to a trapezoid, the triangular heat flux distribution becomes a concave nonlinear fractional function distribution, which is called the concave triangle heat flux distribution model in this paper. Under the size shown in Figure $1, L 1=4.6 \mathrm{~mm}, L 2=2.6 \mathrm{~mm}$, $l_{c}=1.75 \mathrm{~mm}$, four kinds heat flux distributions under different contact areas, concave triangle heat flux distribution in trapezoidal contact area (abbreviated as CT heat - T area), triangular heat flux distribution 
in trapezoidal contact area (abbreviated as $\mathrm{T}$ heat - $\mathrm{T}$ area), triangle heat flux distribution in rectangular contact area (abbreviated as $\mathrm{T}$ heat - $\mathrm{R}$ area), average heat flux distribution in rectangular contact area (abbreviated as A heat - $\mathrm{R}$ area), can be drawn, as shown in Figure 2.

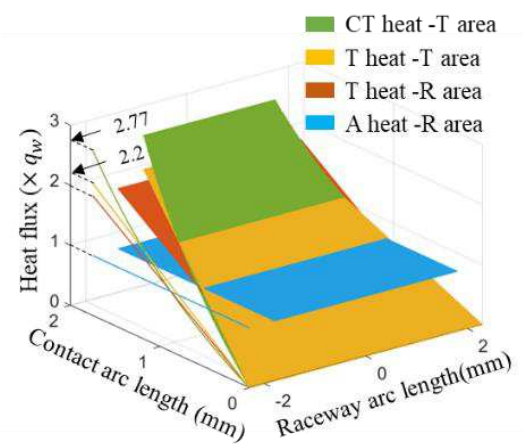

Fig. 2 Different surface heat flux distribution model of grinding contact area

It can be seen from the figure 2 that the maximum heat flux density under different heat flux distribution models is different, and the maximum heat flux density under the concave triangle heat flux distribution in the trapezoidal contact area is the highest, which is 2.77 times the average heat flux density.

Since the grinding depth and grinding arc length of the outer cylindrical surface of the screw are very small compared to the raceway area, the heat flux distribution has little effect on the overall temperature field distribution, so an average heat flux distribution is applied to the outer cylindrical surface for research. Since the outer cylindrical surface on one side of the raceway has been ground and formed, the geometry of the contact area between the grinding wheel and the screw is shown in Figure 3.

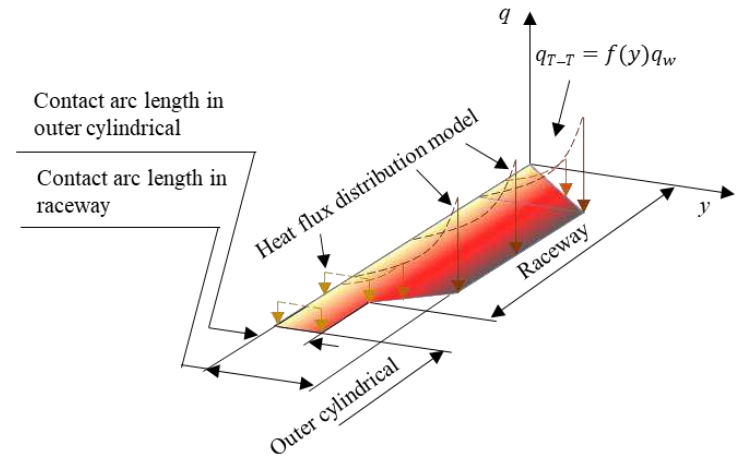

Fig. 3 Grinding contact area on screw helical raceway and outer cylindrical

\section{Experimental Verification of Heat Flux Distribution Model}

Since it is very difficult to measure the grinding temperature and grinding force during the grinding of the helical raceway, in order to verify the accuracy of the different heat flux distribution models, this paper firstly uses the same workpiece material to carry out plane grinding experiments. The changes of grinding temperature and grinding force under different process parameters were measured by thermocouple and dynamometer. The temperature at which the material begins to burn is obtained by observing the ground surface with a microscope. Secondly, the triangular heat flux distribution model is used to carry out the simulation analysis of the temperature field in plane grinding, and the parameters such as the heat distribution ratio and convection coefficient used in the simulation are corrected according to the experimental measurement results. Thirdly, different heat flux distribution models were used to simulate the grinding temperature field of the helical raceway, and the grinding process parameters predicted by different models when reaching the burn temperature are obtained. Then, the helical raceway grinding experiments were carried out using the process parameters, and the burns on the grinding surface under different process parameters were observed. Finally, the accuracy of different heat flux distribution models for predicting burns was compared.

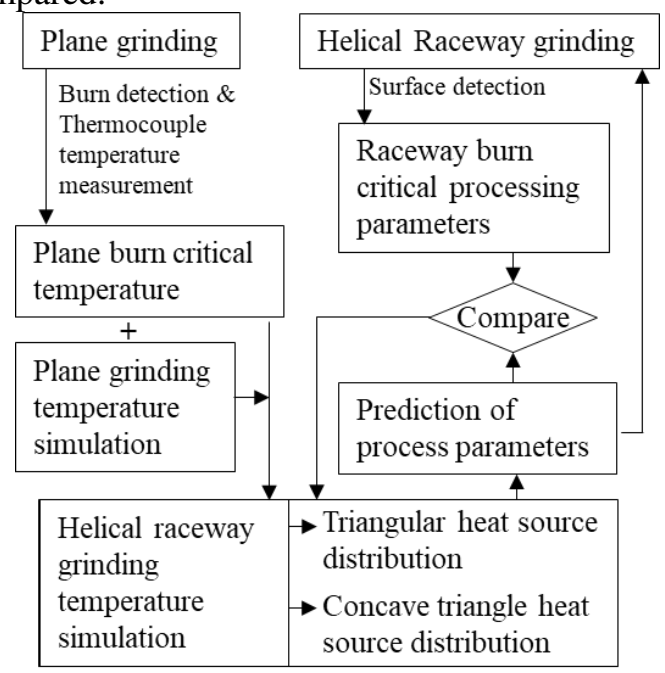

Fig. 4 Model verification flow chart

To make the experimental results of plane grinding have a guiding effect on the grinding of the helical raceway, the grinding environment of the two should be as consistent as possible. Figure 5a shows the plane grinder, workpiece fixture, the grinding force measurement device, and the thermocouple node formed by grinding. Figure 5b shows the thread grinder and how the screw are clamped on the grinder. The $\mathrm{CBN}$ grinding wheel with an average particle size of 120 um was selected for the experiment. The grinding wheel width is $5 \mathrm{~mm}$ and the diameter is $400 \mathrm{~mm}$. 


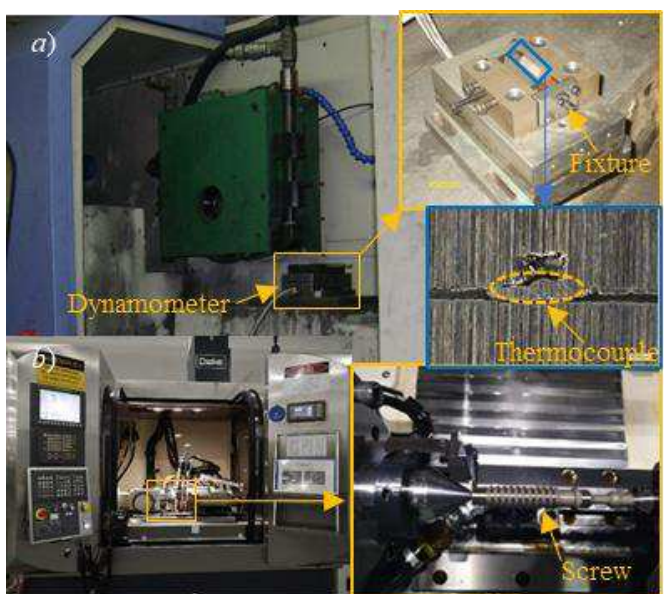

Fig. 5 Experimental equipment (a) plane grinding equipment (b) helical raceway grinding equipment

\subsection{Plane grinding experiment}

The workpiece used in plane grinding experiment is a cuboid with a size of $20 \times 20 \times 30$ $\mathrm{mm}$. In the experiment, two pieces are spliced together, and the grinding experiment is carried out on a plane of $20 \times 60 \mathrm{~mm}$, and a thermocouple is installed on the splicing surface for temperature measurement. Since the removal depth of screw grinding is limited, from the perspective of improving processing efficiency, the grinding depth is set to $0.2 \mathrm{~mm}$. Considering the stability of the grinding machine, the grinding linear speed is selected as $90 \mathrm{~m} / \mathrm{s}$. The grinding force and grinding temperature measured at different feed speed are shown in Table 1.

Tab.1 Grinding experiment process parameters and measurement results

\begin{tabular}{|c|c|c|c|c|c|}
\hline$\dot{0}$ & 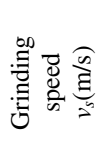 & 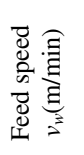 & 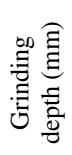 & 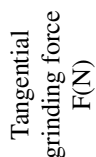 & 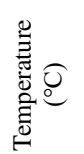 \\
\hline 1 & 90 & 0.5 & 0.2 & 2.5 & 546 \\
\hline 2 & 90 & 1 & 0.2 & 3.5 & 595 \\
\hline 3 & 90 & 1.5 & 0.2 & 5 & 632 \\
\hline 4 & 90 & 2 & 0.2 & 6 & 701 \\
\hline 5 & 90 & 2.5 & 0.2 & 6 & 732 \\
\hline 6 & 90 & 3 & 0.2 & 6.2 & 751 \\
\hline
\end{tabular}

The ground surface was then observed with a microscope, as shown in Figure 6. As can be seen from the figure, the scratches on the ground surface are more pronounced as the feed rate increases, and this change can be explained by the change in the maximum undeformed chip thickness. It can also be seen from the figure that when the grinding speed exceeds $2 \mathrm{~m} / \mathrm{min}$, black burn marks appear on the grinding surface, and the surface quality is obviously deteriorated. Therefore, it can be determined that the critical burn temperature of the workpiece material is between $700^{\circ} \mathrm{C}$ and $730^{\circ} \mathrm{C}$.

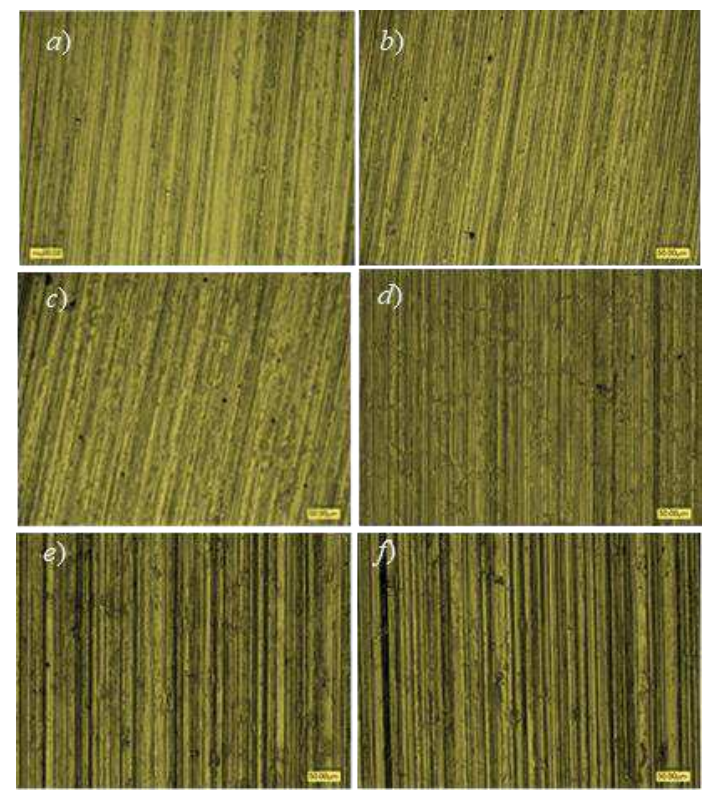

Fig. 6 Surface texture under different grinding feed speed (a) $\mathrm{vw}=0.5 \mathrm{~m} / \mathrm{min}(\mathrm{b}) \mathrm{vw}=1 \mathrm{~m} / \mathrm{min}(\mathrm{c}) \mathrm{vw}=1.5 \mathrm{~m} / \mathrm{min}(\mathrm{d})$ $\mathrm{vw}=2 \mathrm{~m} / \mathrm{min}$ (e) $\mathrm{vw}=2.5 \mathrm{~m} / \mathrm{min}$ (f) $\mathrm{vw}=3 \mathrm{~m} / \mathrm{min}$

\subsection{Simulation of Grinding Temperature}

The finite element analysis software ANSYS was used to solve the transient temperature field generated by the grinding. Due to the small grinding depth, the effect of grinding depth on the temperature field is ignored. The surface thermal effect element SURF151 is covered on the temperature convection surface. Considering that the temperature gradient of the grinding surface is very large, and considering the load applied when the non-uniform heat flux distribution model is used, the mesh of the outer surface of the workpiece and screw are refined, and the mesh of the central area is enlarged to reduce the calculation time. The various parameters used in the heat flux density solution process are shown in Tables.

Tab.2 Thermal physical properties of grinding wheels and

\begin{tabular}{cccc}
\multicolumn{3}{c}{ materials } \\
\hline Material & $\begin{array}{c}\text { Density } \\
\left(\mathrm{kg} / \mathrm{m}^{3}\right)\end{array}$ & $\begin{array}{c}\text { Specific heat } \\
\text { capacity } \\
(\mathrm{J} /(\mathrm{kg} \cdot \mathrm{K})\end{array}$ & $\begin{array}{c}\text { Thermal } \\
\text { conductivity } \\
(\mathrm{W} / \\
(\mathrm{m} \cdot \mathrm{K})\end{array}$ \\
\hline & & & \\
$9 \mathrm{SiCr}$ & 7800 & 450 & 68 \\
$\mathrm{CBN}$ & 3480 & 500 & 1300
\end{tabular}

4.2.1 Plane grinding temperature simulation

Previous studies have shown that the triangular heat flux distribution model can well describe the actual heat flux distribution in the grinding contact area for the surface shallow grinding process. Therefore, this paper adopts the triangular heat flux distribution to simulate and analyze the grinding temperature field of surface grinding. 
a)

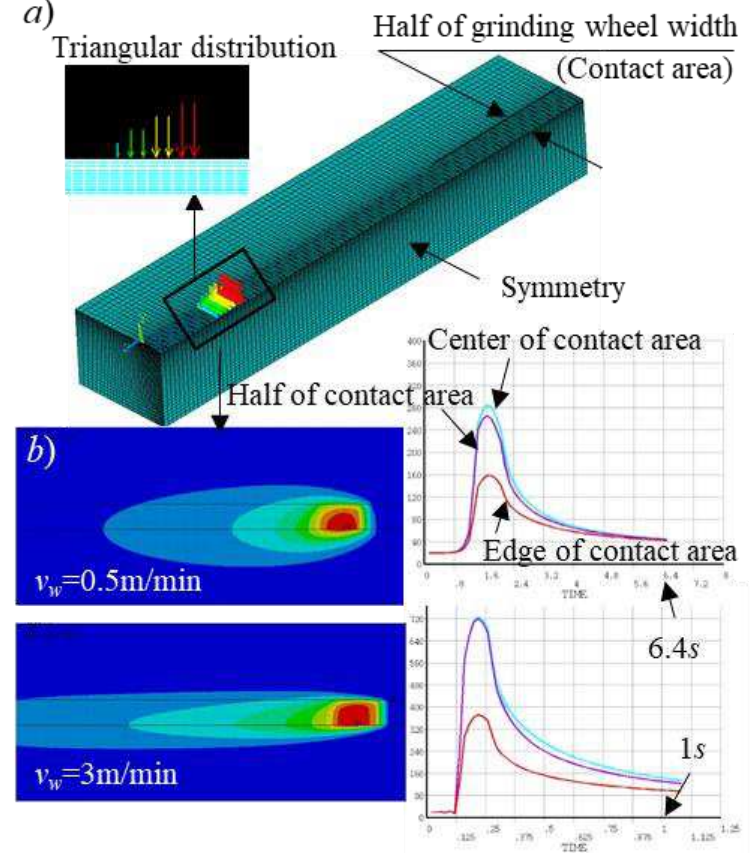

Fig. 7 Plane grinding simulation. (a) Finite element simulation model, (b) Grinding temperature distribution and variation at different feed speed

It can be seen from Fig. 7 that the highest grinding temperature appears at the symmetrical center of the grinding area, and with the increase of the feed speed, the temperature distribution exhibits obvious Doppler effect.

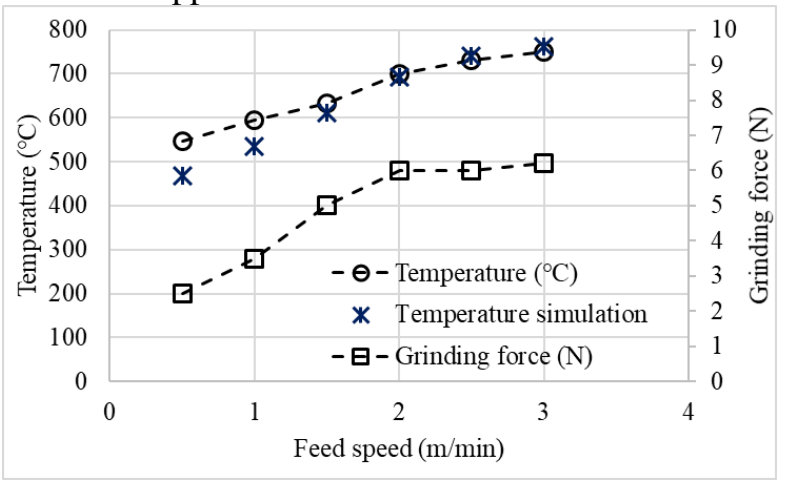

Fig. 8 Measured and simulated grinding temperature and grinding force during plane grinding

According to the introduction of part 2, it can be known that the tangential grinding force and the grinding speed determine the total generated grinding heat. The heat distribution ratio, process parameters, boundary conditions and other factors determine how much heat is introduced into the workpiece, and how much the temperature rise. In order to improve the simulation accuracy, some solution parameters (such as boundary conditions) are adjusted slightly to make the simulation results and the experimental measurement results as consistent as possible near the critical burn temperature. Figure 8 shows the simulated and experimentally measured maximum temperatures as a function of feed rate. It can be seen from Figure 8 that the maximum grinding temperature obtained by the simulation and the experimental measurement results are in good agreement near the critical burn temperature. Therefore, the modified parameter settings are used to simulate the temperature field of the screw raceway.

4.2.2 helical raceway grinding temperature simulation

The geometric parameters of the screw model are shown in Table 3.

\begin{tabular}{cccc}
\multicolumn{4}{c}{ Tab. 3 Geometric parameters of screw model } \\
\hline $\begin{array}{c}\text { Pitch } \\
(\mathrm{mm})\end{array}$ & $\begin{array}{c}\text { Outer cylinder } \\
\text { diameter } \\
(\mathrm{mm})\end{array}$ & $\begin{array}{c}\text { Number of } \\
\text { threads }\end{array}$ & $\begin{array}{c}\text { Raceway circle } \\
\text { radius } \\
(\mathrm{mm})\end{array}$ \\
\hline 4 & 14 & 1 & 1.4 \\
\hline
\end{tabular}

Figure 9a shows the three-dimensional finite element model of the screw. The convection density boundary condition is applied to the helical raceway and the outer cylindrical surface of the screw. In this part, three kinds of heat flux distribution models are compared and analyzed, like applying a triangular heat flux distribution to the rectangular contact area ( $\mathrm{T}$ heat $-\mathrm{R}$ area), applying a triangular heat flux distribution to the trapezoidal contact area ( $\mathrm{T}$ heat $-\mathrm{T}$ area), applying a concave triangle heat flux distribution to the trapezoidal contact area (CT heat $-\mathrm{T}$ area), as shown in Figure 9b. 


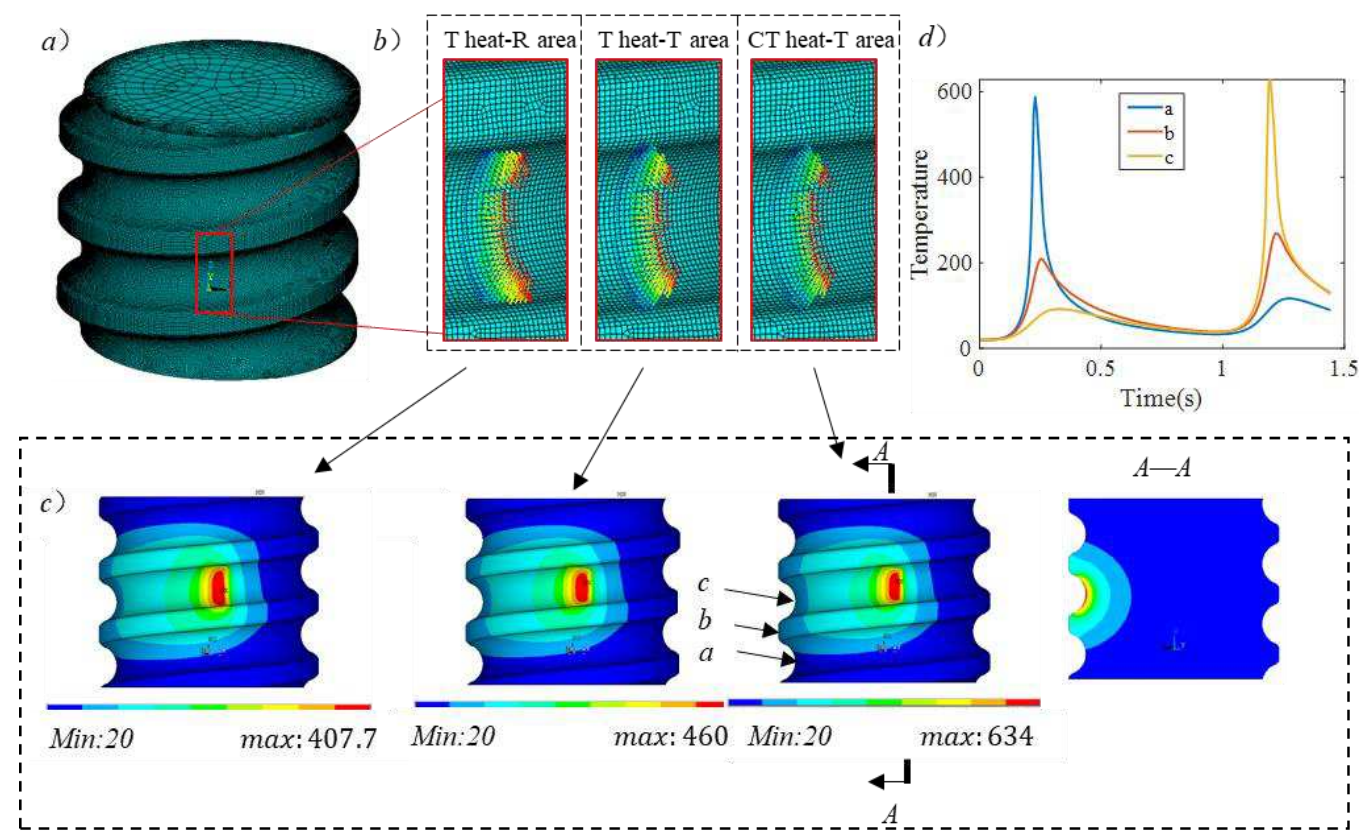

Fig.9 Finite element model and transient temperature field distribution under different heat flux loading methods $(\mathrm{vw}=1 \mathrm{~m} / \mathrm{min})$ (a) finite element simulation model (b) the different heat flux distribution (c) temperature field formed by different heat flow distributions (d) the temperature of different points on the surface of the screw changes with time

According to the simulation results shown in Fig. 9c, it can be seen that the maximum grinding temperature is located in the center of the raceway, and the maximum temperature and temperature gradient of the machined surface obtained by using the concave triangular heat flux distribution are obviously higher than those simulated by the triangular heat flux distribution. This can be used to explain that in the actual grinding process, there is a higher probability of burns when grinding the raceway with the same process parameters than the plane grinding. It can be seen from the crosssectional view of the screw that the grinding temperature is transmitted in an approximate circular surface along the depth direction of the raceway. According to Figure 9d, the spiral raceway is not significantly affected by the grinding temperature of the adjacent raceway, which indicates that the grinding temperature will not cause a significant cumulative increase at this grinding speed.

Different heat source distribution models were used to carry out grinding temperature simulation. The highest temperature at different feed speeds, as shown in Table 4.

Tab. 4 Maximum grinding temperature under different heat flux distribution models and different feed speeds

\begin{tabular}{|c|c|c|c|c|}
\hline$\stackrel{0}{\mathrm{z}}$ & 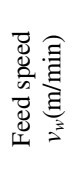 & 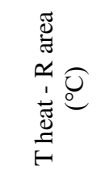 & 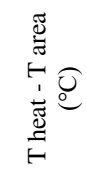 & 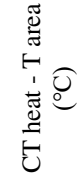 \\
\hline 1 & 1.5 & NAN & NAN & 695.2 \\
\hline 2 & 2 & 687 & 693.99 & 771.1 \\
\hline 3 & 2.5 & 708.576 & 724.68 & 805.2 \\
\hline 4 & 3 & 726.968 & 743.49 & 826.1 \\
\hline 5 & 3.5 & 738 & 753 & NAN \\
\hline
\end{tabular}

It can be seen from Table 4 that when the concave triangle heat source distribution model is used for prediction, the grinding surface will burn when the feed speed exceeds $1.5 \mathrm{~m} / \mathrm{min}$, while when the triangle heat source distribution model is used for prediction, the feed speed should be above $2 \mathrm{~m} / \mathrm{min}$. In order to verify which heat source distribution model is more accurate, experiments of screw grinding under different feed speeds were carried out, and the surface was observed.

\subsection{Helical raceway grinding experiment}

The microscopic topography of the grinding surface under different feed speeds were observed by microscope, and the observation results are shown in the following figure.

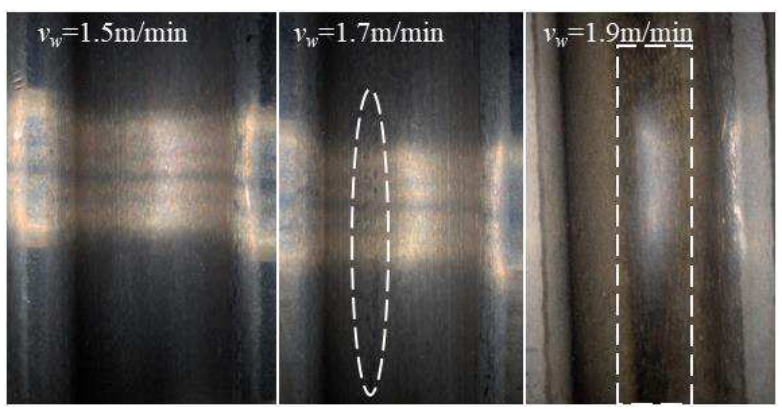

Fig. 10 Grinding surface of helical raceways at different feed speeds

By observing the grinding surface of the helical raceway processed at different feed speeds, it is found that there are no burn marks generated when the feed speed less than $1.5 \mathrm{~m} / \mathrm{min}$, and linearly distributed burn marks can be founded when the feed speed reaches $1.7 \mathrm{~m} / \mathrm{min}$. After multiple inspections, it was found that the linear burns mostly occurred at the bottom of the raceway and the nearby areas, with a certain randomness. The 
analysis believes that this is caused by the partial blockage of the grinding wheel or the falling off and passivation of the abrasive particles, which can be avoided by dressing the grinding wheel. When the feed speed reaches $1.9 \mathrm{~m} / \mathrm{min}$ and above, large continuous black burn marks appear and concentrated in the bottom area of the raceway, which is consistent with the highest temperature area obtained by the simulation.

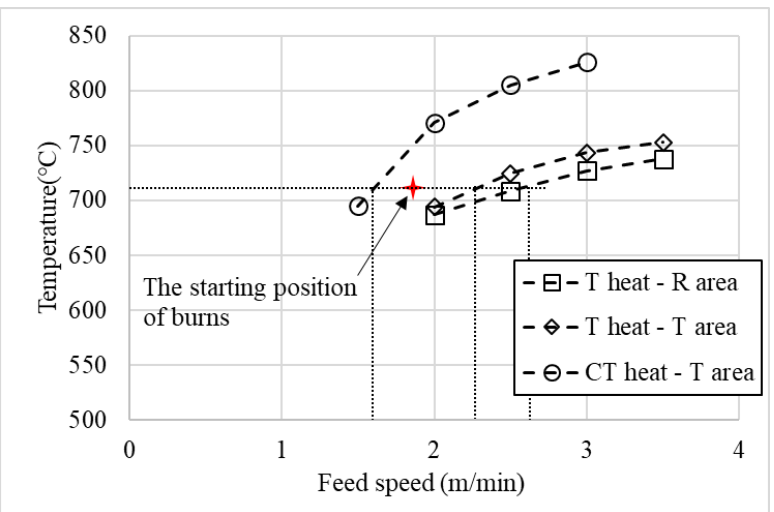

Fig. 11 Simulation results of grinding temperature under different heat flux distribution models and different feed speeds

Figure 11 shows the simulation results of the influence of different heat flux distribution on the grinding temperature. By analyzing the feed speed when the burn is detected on the surface, it can be found that the grinding temperature obtained by applying the concave triangle heat flux distribution model on the trapezoidal contact area is higher than the actual grinding temperature. The grinding temperature obtained by applying the triangle heat flux distribution model on the trapezoidal contact area is lower than the actual grinding temperature. Considering the requirements for processing stability, continuity and reliability in the process of high-efficiency screw grinding, the concave triangle heat source distribution model is used to predict the grinding temperature, which can obtain reliable grinding process parameters, avoid grinding burns and improve production efficiency.

\section{Conclusion}

The following conclusions can be drawn from the above research:

(1) Due to the uneven distribution of the raceway allowance, the grinding contact area is trapezoidally distributed. The maximum temperature of the grinding area calculated by applying the triangle heat flux distribution model on the trapezoidal contact area is larger than the actual grinding temperature. Therefore, optimize the allowance for grinding to avoid the formation of the trapezoidal contact zone is useful for reduce the maximum grinding temperature.

(2) The maximum temperature in the grinding area simulated by the concave triangle heat flux distribution model is higher than the actual temperature. Compared with the triangular heat source distribution model, this model is more reliable in the prediction of grinding process parameters.

(3) Because the grinding allowance at the bottom of the raceway is the largest and the heat flux density is also the largest, the temperature at the bottom of the raceway is the highest, and grinding burns are most likely to occur. Considering that the bottom of the raceway is not the working area, the section profile of the raceway can be optimized to avoid burns.

(4) Since the grinding allowance on the outer cylindrical surface on one side of the raceway is small, the temperature rise caused by the coupling with the side surface of the raceway is not obvious. Adjacent raceways did not cause significant cumulative.

Author contribution: Zongfu Guo wrote the paper and analysed the data. Jun Yi, Xiaoping $\mathrm{Hu}$ gives instruction. Jiugen Wang, Kun Zhao gives instruction and support the experiments.

Funding: The 67th batch of general funding projects of China Postdoctoral Science Foundation (No.2020M671710), Zhejiang Province Public Welfare Technology Application Research Project (No. LGG22E050030), Fundamental Research Funds for the Provincial Universities of Zhejiang (No. GK199900X018), The National Natural Science Foundation of China (No.51905168)

Data availability: This article contains all the data gathered or analysed during this study.

Ethical approval: None of the studies mentioned in this article contain any human participation. Also, no animals were harmed during these experiments.

Consent to participate: The authors consent to participate.

Consent for publication: The authors provide their consent to publish this article.

Competing interests: The authors declare no competing interests.

\section{References}

[1] BRINKSMEIER E , MUTLUGUNES Y , KLOCKE F, et al. Ultra-precision grinding[J]. CIRP 
Annals-Manufacturing Technology, 2010, 59(2) : 652-671.

[2] SHORE PMORANTZ P. Ultra-precision Enabling our future[J]. Philosophical Transactions, 2012 , 370(1973): 3993-4014.

[3] SHORE P, CUNNINGHAM C DEBRA D, et al. Precision engineering for astronomy and gravity science[J]. CIRP Annals-Manufacturing Technology, 2010, 59(2): 694-716.

[4] Jaeger JC. Moving sources of heat and the temperature at sliding contacts. Proceedings of the Royal Society of New South Wales 1942; 76: 203-24.

[5] Zhang X, Lin B, Xi H. Validation of an analytical model for grinding temperatures in surface grinding by cup wheel with numerical and experimental results. Int J Heat Mass Transf - Theory Appl 2013;58(1-2):29-42. [6] Pang J, Li B, Liu Y, et al. Heat flux distribution model in the cylindrical grinding contact area. Procedia Manuf 2016;5:158-69.

[7] Li HN, Axinte D. On a stochastically graindiscretised model for 2D/3D temperature mapping prediction in grinding. Int $\mathrm{J}$ Mach Tool Manu 2017;116:60-76.

[8] He YH, Xu YB, Tang JY, et al. Study on heat flux distribution model of high-order function in grinding arc area. Chin J Mech Eng-En 2018;55(7):199-206.

[9] Yi J, Jin T, Deng ZH. The temperature field study on the three-dimensional surface moving heat flux model in involute gear form grinding. Int $\mathbf{J}$ Adv Manuf Tech 2019;103(5-8):3097-108.

[10] Miao Q, Li HN, Ding WF. On the temperature field in the creep feed grinding of turbine blade root: simulation and experiments. Int $\mathbf{J}$ Heat Mass Transf Theory Appl 2020;147:118957.

[11] Jin T, Stephenson D J. Investigation of the heat partitioning in high efficiency deep grinding. International Journal of Machine Tools and Manufacture, 2003, 43(11): 1129-1134.
[12] Malkin S, Anderson R B. Thermal Aspects of Grinding: Part 1-Energy Partition[J]. Journal of Engineering for Industry, 1974, 96(4):1177.

[13] W.B. Rowe, M.N. Morgan, S.C.E. Black, B. Mills. A Simplified Approach to Control of Thermal Damage in Grinding. Annals of the CIRP, 1996, 45(1);299 302 [14] Bei Jiyao. Analysis and study of grinding temperature. Journal of Shanghai Jiao Tong University, 1964, 28(3): 45-49

[15] Kim H J, Kim N K, Kwak J S. Heat flux distribution model by sequential algorithm of inverse heat transfer for determining workpiece temperature in creep feed grinding. International Journal of Machine Tools and Manufacture, 2006, 46(15): 2086-2093

[16] Zhou Z, Mao C, Zhou D, et al. Experimental Investigation of Grinding Temperature and Its Effects on Surface Quality in Surface Grinding[J]. China Mechanical Engineering, 2008.

[17] Li B, Zhu D, Pang J, et al. Quadratic curve heat flux distribution model in the grinding zone. The International Journal of Advanced Manufacturing Technology, 2011, 54(9-12): 931-940 